NIST Economic Analysis Brief 8

\title{
NIST Technology Transfer Interactions: Fiscal Year 2010 through Fiscal Year 2014
}

Isaac Patterson (isaac.patterson@nist.gov)

Nicole Gingrich (nicole.gingrich@nist.gov)

Jimmy Nazario-Negron (jimmy.nazario-negron@nist.gov)

Technology Partnerships Office, Innovation \& Industry Services

\section{Key Findings}

- NIST interacted more than 300,000 times with domestic institutions from fiscal year 2010 through fiscal year 2014.

- NIST involved itself directly in 68,478 interactions on average each year throughout the United States.

- NIST connected with 6,731 unique, domestic institutions on average each year.

\section{Introduction}

Each year NIST interacts with a variety of academic institutions, private businesses and government entities in the pursuit of its mission to promote U.S. innovation and competitiveness ${ }^{1}$. Information about the number of interactions among NIST and its partners and customers is important in understanding the breadth and impact of NIST laboratories, measurements, and services across the U.S. economy. Examining the types of interactions, including grants, awards, research agreements, technical services, education and purchased products between NIST and its partners can demonstrate the true size of NIST's footprint.

NIST works directly with private businesses, academic institutions and government entities in a variety of ways; therefore, there are many avenues through which NIST can impact actors in the U.S. economy. The total number of annual interactions and the extent to which these interactions are dispersed geographically was previously unknown. In this study, we provide the annual number of NIST's interactions in several categories and the country-wide, geographical distribution of NIST's customers and partners, demonstrating the extent of NIST's reach in the U.S. economy.

\section{Methodology}

A list of methods by which NIST interacts with its partners and customers was developed. The types of interactions primarily fell into one of four classifications: education, research, products or services. Educational interactions consist of authoring publications and hosting conferences. Research-driven interactions involve research

${ }^{1}$ NIST Mission, Vision, Core Competencies, and Core Values 
participants of the Center for Nanoscale Science and Technology (CNST) and NIST Center for Neutron Research (NCNR), research associates, and Cooperative Research and Development Agreements (CRADAs). NIST products available for sale include Standard Reference Materials, Standard Reference Data, calibrations and licenses. NIST services include grants and Small Business Innovation Research Program (SBIR) Awards.

These 12 interaction types were used as indicators of direct relationships between NIST and the U.S. economy. To retrieve information about the number and location of NIST partners, an isolated data request was performed throughout various administrative areas for fiscal years (FY) 2010 through 2014 for each interaction type. Because this was a separate request, the numbers reported differ slightly from the Department of Commerce's annual technology transfer report. ${ }^{23}$

Statistical analysis of the information received was performed to summarize the numbers of NIST's U.S. partners and customers for each year of the study. Geographic locations for each were obtained either as part of the data request or in an independent search.

\section{Economic Analysis}

The average number of interactions in which NIST engages each year with its partners/customers is shown in Figure 1 below. Total interactions of all years in the study exceeds 300,000 . Of the 12 interaction types identified for use in this study, the average number of interactions, from fiscal year 2010 through 2014, is 68,477 annually. For the same 5-year period, the average number of individual partners/customers annually is 6,730 (see Table 1 in Appendix A).

\footnotetext{
${ }^{2}$ Annual Report on Technology Transfer: Approach and Plans, Fiscal Year 2016 Activities and Achievements

${ }^{3}$ See additional information regarding the data in Appendix B.
} 
Figure 1 - NIST Technology Transfer Interactions: Averages by Interaction Type (FY 2010 through FY 2014)
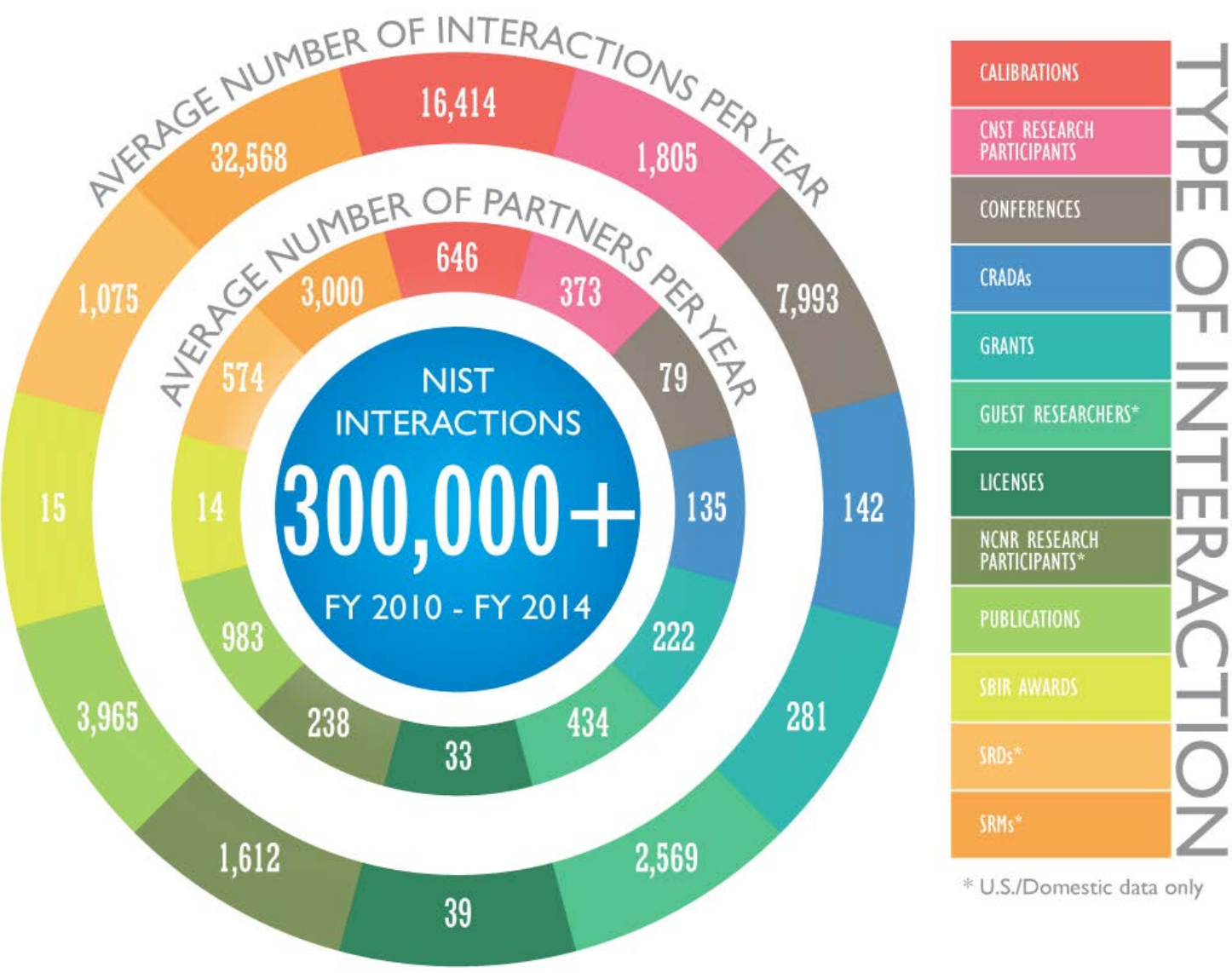

The number of annual interactions between NIST and its partners provides an important source of information for examining the scope of NIST's impact in the U.S. economy. NIST reaches many diverse partners each year in a variety of ways, providing evidence of the size of NIST's footprint on the U.S. economy.

The geographic distribution of the institutions with which NIST interacts indicates the wide-spread influence that NIST services have domestically (Figure 2). Interactions are distributed across the United States, from Silicon Valley to the Northeastern Corridor, and everywhere in-between. Blue circles on the map indicate the cities where NIST's partners and customers are located, while the heat-map color scheme of the states shows the number of unique partners and customers in each state over the time-period.

NढT

Nationatitute of Standards and Technology 


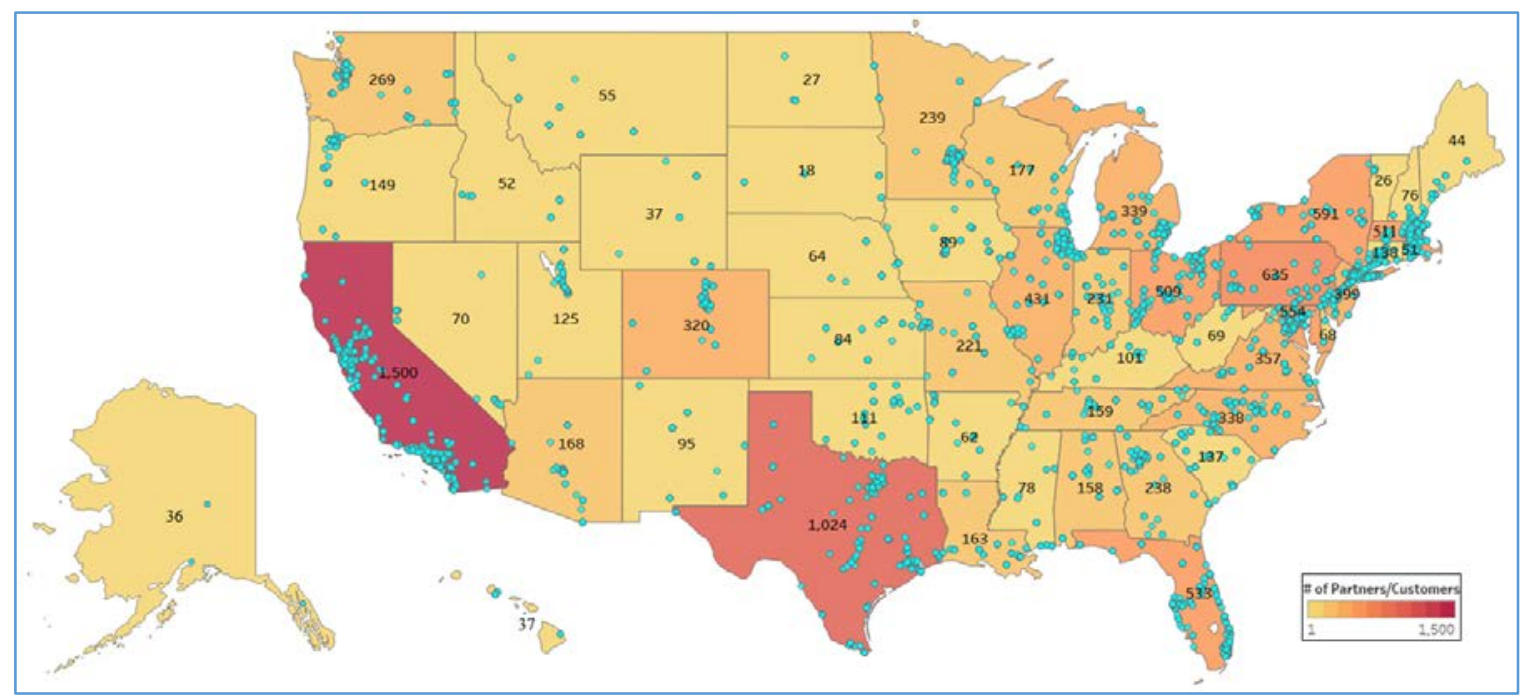

\section{Summary}

The findings of this study show that NIST provides a broad level of influence across the U.S. economy. There are consistently high numbers of interactions between NIST and its partners and customers year after year. The diversity in the types of these interactions gives further evidence that NIST is providing a wide range of education, research, products and services to the U.S. economy.

The geographic distribution of NIST's interactions show the wide range of influence that it has within the US economy. Regional clusters exist in areas known to foster research, technology and innovation. These interactions aid in the fulfillment of its mission of improving the growth and innovation of the U.S. economy.

\section{Looking Forward}

In the future, this high-level overview of total NIST interactions could be broken into smaller categories of partner type such as industry, government and academia. This differentiation would allow a more precise understanding of the types of partners with which NIST interacts and their geographic locations.

Different organizational units within NIST have different focus areas. It may be useful for NIST to understand who and where their current collaborators are, as well as who and where their collaborators may be in the future. This information is useful for meeting the goals within NIST's Programmatic Plan ${ }^{4}$. Analyses in the future could indicate the

${ }^{4}$ NIST Three Year Programmatic Plan 2017-2019

NLT

National Institute of Standards and Technology 
county or congressional district of each partner, which may be helpful for assessing NIST's impact on partners and customers at state and local levels.

\section{References}

Annual Report on Technology Transfer: Approach and Plans, Fiscal Year 2016 Activities and Achievements. (2017, September). Retrieved October 31, 2017, from https://www.nist.gov/file/385106

NIST Mission, Vision, Core Competencies, and Core Values. (2017, January 26). Retrieved October 31, 2017, from https://www.nist.gov/about-nist/ourorganization/mission-vision-values

NIST Three Year Programmatic Plan 2017-2019. (n.d.). Retrieved January 10, 2017, from https://www.nist.gov/sites/default/files/documents/director/planning/3_year_plan_ 2017-19_web_ready2.pdf 


\section{Appendix A}

Table 1 - NIST Technology Transfer Interactions: Averages and Standard Deviations (FY 2010 through FY 2014)

\begin{tabular}{|c|c|c|c|c|}
\hline Interaction Type & \multicolumn{2}{|c|}{ Partners/Customers } & \multicolumn{2}{|c|}{ Interactions } \\
\hline & Average & $\begin{array}{c}\text { Standard } \\
\text { Deviation }\end{array}$ & Average & $\begin{array}{c}\text { Standard } \\
\text { Deviation }\end{array}$ \\
\hline Calibrations & 646 & 66 & 16,414 & 1,318 \\
\hline $\begin{array}{c}\text { CNST } \\
\text { Research Participants }\end{array}$ & 373 & 83 & 1,805 & 452 \\
\hline Conferences & 79 & 9 & 7,993 & 892 \\
\hline CRADAs & 135 & 53 & 142 & 56 \\
\hline Grants & 222 & 25 & 281 & 41 \\
\hline Guest Researchers & 434 & 24 & 2,569 & 42 \\
\hline Licenses & 33 & 3 & 39 & 2 \\
\hline NCNR & 238 & 8 & 1,612 & 115 \\
\hline Research Participants & 983 & 42 & 3,965 & 244 \\
\hline Publications & 14 & 2 & 15 & 2 \\
\hline SBIR Awards & 574 & 104 & 1,075 & 287 \\
\hline SRDs & 3,000 & 40 & 32,568 & 662 \\
\hline SRMs & 6,730 & & 68,477 & \\
\hline TOTAL & & & & \\
\hline
\end{tabular}

NLTT

National Institute of Standards and Technology
U.S. Department of Commerce 


\section{Appendix B}

\section{Clarifications in the Dataset:}

- The number of conferences and the number of conference attendees is reported for this subset of data. Although conference attendees often attend on behalf of a business or institution, these affiliations are not consistently reported. Therefore, only conference attendees are counted as individual interactions.

- The information for CRADAs includes only traditional CRADAs issued by NIST. Other CRADA types, such as Material Transfer Agreements, are not included.

- The data for grants is retrieved from the www.grants.gov website.

- SRM data is the total number of standard reference material units sold.

- All active licenses are used to generate license data for each fiscal year.

- Publications data represent the number of unique institutions and/or the number of non-NIST co-authors involved in each publication.

- Both phase I and phase II SBIR awards are used for SBIR data.

- Standard Reference Data includes E-Commerce orders only.

- CNST Research Participants data are for participants with direct involvement or collaboration in research experiments or projects. This research can be done via on-site or remote access to the facility.

- NCNR Research Participants data are for participants with direct involvement or collaboration in research experiments or projects. This research can be done via on-site or remote access to the facility.

- Guest Researchers are the total number of researchers hosted by NIST to collaborate on scientific projects. These include researchers with term appointments and those classified as non-NIST employees.

- Calibrations data is comprised as the total of calibration services, special physical measurement tests and measurement assurance programs ${ }^{5}$.

${ }^{5}$ Annual Report on Technology Transfer: Approach and Plans, Fiscal Year 2016 Activities and Achievements

NاكT

titute of Standards and Technology
U.S. Department of Commerce

National Institute of Standards and Technology

Dr. Walter Copan, NIST Director and Under Secretary of

Commerce for Standards and Technology 